\title{
Experiences of people affected by rabies in Ethekwini district in the province of Kwazulu-Natal, South Africa
}

\author{
Jeffrey Mduduzi Hadebe ${ }^{1}$, Maureen Nokuthula Sibiya ${ }^{2}$
}

1. Durban University of Technology - Steve Biko Campus, Nursing.

2. Durban University of Technology, Faculty of Health Sciences.

\begin{abstract}
Background: South Africa is one of the countries in Africa adversely affected by rabies, a notifiable disease which can be fatal. Fatalities can be prevented if health care is sought timeously and people are educated about the disease. The Province of KwaZulu-Natal, in particular, has had rabies outbreaks in the past which have led to loss of many lives and devastation of entire families.
\end{abstract}

Objective: The aim of the study was to explore the experiences of people affected by rabies in the eThekwini district of KwaZulu-Natal, South Africa.

Methods: The study was guided by a qualitative, exploratory, descriptive design. The sample was purposively selected, and a semi-structured interview was used to collect data from people affected by rabies in the eThekwini district. Data saturation was reached after 12 participants were interviewed. Data was analysed by using Tesch's eight steps of thematic analysis.

Results: The themes included family stability and support structures, exposure to risk factors and risky practices, factors that hindered participants from seeking health care assistance, limited knowledge about rabies and the effects of rabies.

Conclusion: It was evident that participants experienced many challenges during their rabies exposure. Individuals, who were directly affected by rabies through contact with rabid animals, were expected to take responsibility for their own lives.

Keywords: Rabies, South Africa, qualitative research.

DOI: https://dx.doi.org/10.4314/ahs.v20i1.20

Cite as: Hadebe JM, Sibiya MN. Experiences of people affected by rabies in Ethekwini district in the province of Kwazulu-Natal, South Africa. Afri Health Sci. 2020;20(1):150-7. bttps:/ / dx.doi.org/10.4314/abs.v20i1.20

\section{Introduction and background}

Rabies is a notifiable zoonotic disease that is transmitted from animal to animal, and from animal to human through bites from infected (rabid) animal species ${ }^{1,2}$. Rabies is fatal, but preventable $e^{3}$ and rabies is responsible for up to 59000 deaths annually ${ }^{5}$. Rabies is prevalent in under-served populations, both rural and urban ${ }^{4}$. Since the vaccination schedule for dogs is a three-year cycle, there is always a possibility of an outbreak every three years. To prevent the loss of human lives, the Department of Health should adopt a proactive approach. If the experiences of humans exposed to rabies are not studied and published, the attitude and the experiences of the

\section{Corresponding author:}

Maureen Nokuthula Sibiya, Durban University of Technology,

Faculty of Health Sciences.

Email: nokuthulas@dut.ac.za community members towards this disease may remain unchecked. Rabies action group conducted an awareness campaign around eNgonyameni, Adams, KwaMakhutha, and Illovo in 2011, in response to the rabies outbreak that took place, and it was discovered that many community members did not have a clear understanding of rabies and its consequences. ${ }^{23}$

\section{Problem statement}

Dog bites are globally under-reported ${ }^{6}$. South Africa is one of the countries where rabies is endemic ${ }^{7}$. In South Africa, from 1984 to 2000 rabies claimed 226 lives $^{8}$. A rabies outbreak in 2012 claimed 12 victims in KwaZulu-Natal (KZN). Four of the victims were from eThekwini district, with one survivor who has neurological disorders. According to Jibat et al. ${ }^{9}, 70 \%$ of the dog population should receive adequate vaccination coverage annually, to obtain herd immunity and for prevention of a possible outbreak. The researcher sought to explore the experiences of the individuals who were exposed to rabies and also explore the challenges faced by their families. 


\section{Aim of the study}

The aim of the study was to explore the experiences of people affected by rabies in the eThekwini district of KwaZulu-Natal, South Africa.

\section{Methodology \\ Design \\ Qualitative approach and paradigm}

The study was guided by a qualitative, exploratory, descriptive design ${ }^{10}$. A constructivist paradigm was adopt$\mathrm{ed}^{13}$.

\section{Researcher characteristics and reflexivity}

The researcher endeavoured to be as objective as possible and not allow his academic and work experience to interfere with the data analysis and findings.

\section{Setting}

Data was collected from the eThekwini district, a metro that comprises urban, semi-urban and rural areas. People of e'Thekwini keep pets like cats and dogs for various reasons. For example, in rural areas, dogs are kept for hunting whereas in urban and semi-urban areas dogs are kept for security reasons.

\section{Population and sampling}

According to the e'Thekwini Municipality Integrated Development Plan (IDP) Annual Review 2016/2017, the estimated population size of eThekwini for 2017 was 3723 43511. The sample participants were purposively selected. People affected by rabies in eThekwini district and who met the inclusion and exclusion criteria formed the sample. The sample consisted of 12 participants after data saturation. The criteria included individuals exposed to rabies from the eThekwini district, mentally healthy individuals affected by rabies in the eThekwini district, family members of individuals who were exposed to and were affected by rabies from 2011 onwards and individuals who were 18 years and older.

\section{Ethical considerations}

The research commenced after full ethics clearance was granted by the Durban University of Technology Institutional Research Ethics Committee (IREC 118/17). Informed consent was obtained from the participants after an explanation about the content of the study was given. Participants were also informed that they could withdraw at any stage of the research. To ensure beneficence, the researcher shared the study outcomes and the recommendations with participants. The participants were assured of the expediency of their contribution ${ }^{15}$. To ensure self-determination, the researcher treated all the participants with respect by addressing them by their preferred titles or names ${ }^{15}$. The researcher was willing to respect and accept any of the participant's decisions including a wish to pull out of the study. To ensure justice, the researcher treated all participants equally.

\section{Data collection}

Data was collected between November 2017 and January 2018. The researcher used a semi-structured interview schedule to conduct in-depth face-to-face interviews with the participants. An interview guide with pre-set, open-ended questions, with allowance for additional probing questions during the interview was used ${ }^{12}$. The interview guide was translated into isiZulu which is the predominantly spoken language in the KZN province. To ensure credibility of the study, these questions were translated back into English.

Interviews were conducted at the participants' homes. A voice recorder was used during the interview sessions. Each interview session lasted for about an hour. Interviews were conducted to a point of data saturation, where no new information emerged.

\section{Data analysis}

Data was analysed by using Tesch's eight steps of thematic analysis ${ }^{13}$. Data analysis was conducted before the themes were developed. The researcher read through all the transcripts to get a general impression of the collected data. Any thoughts that emerged from the data were written down in the margin. A list of all topics was compiled and similar topics were clustered together. Preliminary organisation of the topics as major topics, unique topics and leftover topics was conducted. Any topics or codes that emerged were written next to the appropriate segment of the text. The most descriptive wording for the topics were used and were then turned into sub-categories. Related topics and emerging list of categories were grouped together. Preliminary analysis of data was conducted by assembling data that belonged to each category from which themes emerged. Existing data was re-coded. 


\section{Trustworthiness}

To ensure trustworthiness in data collection, the criterions stated by Lincoln and Guba (1985 cited in Polit and Beck ${ }^{10}$ were followed. To ensure credibility, the researcher bracketed existing knowledge, pre-conceived ideas and personal views regarding the existing problems. The data was validated with the participants to avoid misquotes, and to ensure that the data was a true reflection of what transpired during the interview. The transcripts and voice recordings were compared and analysed with the supervisor and is archived for future reference. During report writing, voice recordings were re-played repeatedly to ensure that all the information was transcribed.

To ensure dependability, an audit trail was maintained through safekeeping of raw data of each interview for future reference. The supervisor audited the data collected. The study was subjected to peer debriefing and peer review to eliminate the researcher's biases. According to Lincoln and Guba (1985 cited in Polit and Beck) ${ }^{10}$, dependability is a proof that the study is credible and will yield similar results if repeated ${ }^{14}$. The researcher's interpretations of the collected data were scrutinised by the research supervisor who acted as an independent coder.
The themes and sub-themes identified by the researcher were contrasted with those identified by the supervisor to ensure conformability. No major discrepancies were identified between the analyses of data. To ensure transferability, a rich and thorough description of the research setting, study participants and research processes was provided. All participants were treated in a manner the researcher himself would have liked to be treated in a similar position.

\section{Results}

Participants comprised individuals from semi-rural areas, and sub-urban areas in the e'Thekwini district. Some participants were isiZulu-speaking while other participants were using English as their first language. A total of 12 interviews were conducted. Data saturation was reached during the tenth interview. An additional two interviews were conducted to confirm data saturation. Participants were directly or indirectly affected by rabies. Eight interviews were conducted with participants who were indirectly affected (family members) and four were directly affected (patients as a result of dog bites). Five major themes emerged from data collection and each theme had several sub-themes.

Table 1: Emerged themes and sub-themes

\begin{tabular}{|l|l|}
\hline Major Theme & Sub-theme \\
\hline 1. Family background and support. & $\begin{array}{l}1.1 \text { Socio economic status. } \\
1.2 \text { Social beliefs. }\end{array}$ \\
\hline 2. Predisposing factors and risky practices. & $\begin{array}{l}2.1 \text { Social misconceptions. } \\
2.2 \text { Unsafe gestures and practices. } \\
2.3 \text { Abandoning animals. }\end{array}$ \\
\hline 3. Hindrances in seeking assistance. & $\begin{array}{l}3.1 \text { Lack of income. } \\
3.2 \text { Attitudes towards animal } \\
\text { bites. }\end{array}$ \\
\hline 4. Knowledge about rabies and expectations from officials. & $\begin{array}{l}4.3 \text { Unavailability of resources. } \\
\text { Role played by the officials. }\end{array}$ \\
\hline 5. Effect of rabies on the individuals. & $\begin{array}{l}\text { Availability of health support } \\
\text { resources. }\end{array}$ \\
\hline & $\begin{array}{l}5.1 \text { Expression of inner feelings. } \\
\text { Periods of uncertainty and } \\
\text { anxious moments. }\end{array}$ \\
& $\begin{array}{l}5.3 \text { Coping with rabies. } \\
5.4 \text { Awareness of rabies and } \\
\text { rabies control measures. }\end{array}$ \\
\hline
\end{tabular}




\section{Theme 1: Family background and support}

This theme in the study emerged from participants' stating their experiences of the effect of rabies on their family circumstances. Participants communicated the challenges relating to their socio-economic status:

'I am in a difficult position because I cannot even work, I have to take care for my baby day and night. If I were to leave, I have to ask for a guardian.' (P1, caregiver, 51 years old)

The child was permanently disabled as a result of being infected with rabies and her husband, who was the breadwinner, suffered from depression and died from rabies. The participant was left in debt. The family now survives on a monthly grant for the patient and his siblings.

Another participant was also struggling to make ends meet as evident from this excerpt:

'This was something unexpected, and we were financially affected because we had to borrow money, to go to hospital.' (P7, caregiver, 42 years old)

Other participants reported that they preferred private institutions over public, even though they were aware of the financial implications. The following statement was made:

'Well it was quite an expensive experience. I went to a private hospital...I do believe one can go a government hospital and get treatment free of charge. Personally, my choice is that I go and pay at the hospital because it is just around the corner. ... At the end it cost me nearly R4000...' (P9, victim, 72 years old)

The study highlighted the adverse experiences of participants who came from poor socio-economic backgrounds, with no breadwinners and financial constraints. Often, their budget for living ended up being utilised for transport to health institutions and health care, and in some instances they had to borrow money.

\section{Theme 2: Predisposing factors and risky practices}

Some of the participants raised concerns about some practices that had a potential of putting some individuals at risk of contracting rabies. The following statements from two of the participants illustrate that some community members engage in risky practices which put them at risk:

'...some community members believe that to heal shortness of breath, one had to drink water after the dog, sharing the container...' (P3, caregiver, 21 years old).
'People have a belief that a dog bite would can be treated by burning dog hair and rub it on the wound and that bring fast relief (P8, caregiver, 47 years old)

Some community members' acts of kindness to animals can put their own lives in danger. An observation by a participant:

'...People pick stray dogs on the side of the road, and they think they are doing everybody a big favour... They need to know that rabies is a very serious thing...' (P9, victim, 72 years old)

Other participants reported the following risky practice: 'We have a neighbour who keeps a large number of dogs but never vaccinate them ... we even suspect she is rabid herself. Some of her dogs have died after being involved in a fight with other dogs.' (P6, caregiver, 45 years old)

Participants raised concerns about the unknown animals that were roaming around and posing a threat to the community. Their concerns are expressed in the following excerpts:

'We are now on bigh alert...we do not want strange dogs to come into contact with our dogs... once the dog does a damage, it is disowned, and no one want to take responsibility.' (P5, victim, 30 years old).

'Initially it appeared that the havoc was caused by a stray dog, however later it was discovered that it was a dog from the neighbourhood and the owner was known. During the time of the incidence no one took responsibility.' (P7, caregiver, 42 years old)

Theme 3: Hindrances in seeking assistance. The study revealed that there were instances when community members and participants could not seek medical intervention. Unemployment and lack of financial support are factors which contributed to community members' reluctance to seek medical help. Participants shared their experiences with regards to the economic status of their families:

'We were really affected financially because we are all unemployed in this house...' (P6, caregiver, 45 years old)

My father lost the urge to proceed with the treatment schedule, because the hospital is far away and according to him the dog bite was a minor thing ... taxi fare costs was an issue.' (P10, caregiver, 29 years old)

\section{Attitude towards animal bites}

The results of this study indicate that some participants did not take dog bites seriously. Self-medication was pre- 
ferred to professional health care. The following statement alludes to this fact:

'My father took it very lightly, because it was a small wound on the arm. He stated that he was going to use herbal concoction on the wound and he will be fine....' (P10, caregiver, 29 years old). Such statements indicate that some individuals may not seek medical help.

\section{Unavailability of resources}

From the participants' point of view, lack of medical supplies causes inconvenience and possibly even death. These two excerpts illustrate this:

'We sent the child to hospital and we were told that she was supposed to get two injections... One was out of stock and only one was administered... I believe that if my child received all the necessary treatment when we visited the health facility she was not going to pass on.' (P8, caregiver, 47 years old)

'I strongly believe that my father would still be alive if the necessary treatment was available at the health facility...' (P10, caregiver, 29 years old)

\section{Theme 4: Knowledge about rabies and expectations from officials}

Participants expressed their feeling of dissatisfaction with the promises made by health officials during the rabies outbreak. During outbreaks, health officials feed information to the health authorities who speak on behalf of the department. Interaction between the community members and the Department of Health representatives takes place. The following statements were gathered from the participants:

'we were promised a fully furnished house but all we got was a house without furniture...I wish taking advantage of people who need help must end.' (P3, caregiver, 21 years old)

'For seven years I have stayed here, there has been not a single dog vaccination campaign in this area.' (P10, caregiver, 29 years old)

'I do not think the rabies control measures are adequate... a lot of areas should be covered for vaccination so that we will have peace of mind... dogs reproduce constantly, and the relevant department should at least vaccinate monthly.' (P8, caregiver, 47 years old)

Health resources should be adequate and available to sustain community needs and demands. Participants had the following opinions about the availability of health resources:

'We wish that the health facilities should have all the medications available at all times...' (P10, caregiver, 29 years old)
'I think there should be a shift from the normal practice, because it seems the current control measures are not powerful enough... (P4, victim, 24 years old)

\section{Theme 5: Effect of rabies on the individual}

Participants related experiences of how rabies affected their lives; for some participants their normal routines changed. From the experiences shared by the participants, it was evident that there were elements of desperation and pain. One participant, referring to the rabies survivor she was caring for, stated:

'It is very painful because as it is he is bedridden and cannot do anything for himself. He cannot go to school, he is missing out, and his peers are progressing and he cannot do anything .... He is a disabled individual...' (P1, caregiver, 51 years old)

One participant described her mother's peculiar behaviour before she died of rabies:

'...she howled like a dog, she would bite on people and she ripped her clothes apart... She was acting like a dog...We realised after she passed on that she had rabies.' (P3, caregiver, 21 years old)

Some participants were more concerned about the welfare of the animals rather than their own lives, as noted in this excerpt:

'... he [the donkey] did not bite me intentionally, it happened because of me trying to belp him because he appeared ill.' (P9, victim, 73 years old)

Some participants verbalised their fear of dogs:

'I hate dogs and cats, if I see a dog it is as if I am seeing rabies... When the dog approach, I am always tempted to throw a stone at it.' (P10, caregiver, 29 years old)

'We are now very scared of dogs and cats, because whatever actions they display become suspicious...' (P6, caregiver, 45 years old)

Participants indicated that rabies caused confusion in their lives. They reported that they were only made aware of the diagnosis after the demise of their family members, as noted in these excerpts:

'... The child was admitted for about 10 days... he passed on, from then on I feared rabies...' (P8, caregiver, 47 years old)

'The doctor who consulted my mother initially diagnosed joint pains .... The worst part is that we were not aware of what she was suffering from, rabies was only diagnosed after she passed on... (P3, caregiver, 21 years old)

Participants indicated that they experienced challenges that can be attributed to rabies:

'I even failed my second term grade at school (term ending in June). 
Memories affected me adversely.' (P3, caregiver, 21 years old). 'It was very painful because we lost a breadwinner... It is never the same without our father.' (P10, caregiver, 29 years old)

The study revealed that the participants' experiences made them aware of the rabies disease. Participants stated:

'We think. we could have lost the child if we approached a traditional healer.' (P2, care giver, 49 years old). '... we learnt that the dog could be rabid and rabies could kill... We realised that rabies has strong toxins.' (P3, caregiver 21 years old)

'...before the ordeal we were aware of the rabies disease but it was something we had never seen before...' (P8, caregiver, 47 years old)

'...I am far more aware of the consequences, so I am knowledgeable. I know what to do, when to do it and what not to do, I am far more educated?' (P9, victim, 72 years old)

\section{Discussion}

Durrheim et al. ${ }^{16}$ assert that in Africa the human population growth is concurrent with the accelerated dog population growth. According to EThekwini Integrated Development Plan (IDP), eThekwini was experiencing low economic growth, high rates of unemployment, and high levels of poverty ${ }^{11}$. Community members' socio-economic status influenced their decision-making. More than $99 \%$ of all human rabies deaths occur in the poorest developing countries ${ }^{16}$. Lembo et al. ${ }^{17}$ asserts that poor families are disadvantaged in rabies prophylaxis. This is aggravated by the fact that multiple visits must be made to the health facility. About $62 \%$ of Nigerians exposed to dog bites did not visit health facilities for medical intervention ${ }^{18}$. The study also revealed that some community members chose not to vaccinate animals, like dogs, for strange reasons. These findings concur with the study by Lembo et al. ${ }^{17}$ who concluded that there was some unwillingness by the community members to have their dogs vaccinated. Unwillingness to vaccinate animals was also fuelled by the increase of unwanted animals after the death of the owner ${ }^{7,22}$.

Another kind of risky behaviour by the community members was the tendency to pick up stray animals. Stray animals are a big risk for rabies because they may not be vaccinated. The findings of this study concur with $\mathrm{Pye}^{21}$ who stated that individuals should avoid engaging with animals they are not familiar with, no matter how friendly they may seem. Adedeji et al..$^{18}$ found, in their study, that $8.7 \%$ of the community, in their selected setting, believed that herbs could be used to treat rabies infection. This statement is confirmed by this study where one participant's family member tried some herbal concoction to treat himself. Other participants, in this study, complained about the promises that were made by officials during outbreaks which were not met. Adedeji et al..$^{18}$ concurs that some policy makers use deception and manipulation during campaigns for their own benefit. Globally, individuals who succumb to rabies have either received incomplete vaccination or experience delays in receiving the full treatment. Post-exposure prophylaxis without immunoglobulin was identified as one of the main reasons for rabies fatalities ${ }^{19}$. The Department of Health through the National Core Standards asserts that stock and suppliers are efficiently managed to ensure supplies meet planned service needs at all times ${ }^{20}$.

Some participants stated they had eerie feelings towards unknown or strange animals in their vicinity. Lembo et al. ${ }^{17}$ agree with these findings by stating that individuals who have been previously exposed to rabies often develop fear of dogs. For these participants, any unknown animal is a potential threat. Adedeji et al. ${ }^{18}$ states that rabies preventative measures should include community participation in public health education and sharing of experiences. Lembo et al. ${ }^{17}$ argues that there is a marked lack of knowledge on the issue of human rabies globally. This study showed that exposure to rabies and experiencing the consequences, empowered families with knowledge and confidence.

\section{Recommendations}

Health dialogues with stakeholders and mass health education campaigns, involving all stakeholders, should be conducted. The potential of a rabies outbreak in a threeyear cycle necessitates an annual review of animal vaccination schedules. A plan should be developed to control rabies among wild animals. By-laws should be strictly enforced at community level, with steep penalties for individuals who contravene them. For example, fencing of premises by animal keepers, putting dogs on a leash as prescribed, caring for animals and not abandoning them, and vaccination of animals at regular intervals should be enforced. Further research on this topic, on a wider scale, is recommended. 


\section{Conclusion}

This study revealed that most people who were exposed to rabies gained more knowledge or information only after exposure. The health systems appeared to be reactive rather that proactive with regards to rabies. It was also evident that the participants went through such challenging times during their rabies exposure that some are still caring for those affected by rabies and continue to experience challenges because of lack of support. The study found that there were irresponsible animal owners who ignored the safety protocols of animal vaccination. It was also found that helping stray animals can have fatal consequences and people needed to be cautious. The reasons for the demise of some of the participants' family members was lack of knowledge about rabies, financial constraints, and unavailability of anti-rabies treatment at health facilities.

\section{Acknowledgements}

The researchers wish to acknowledge the Durban University of Technology for funding the study.

\section{Competing interest}

The authors declare that they have no financial or personal relationship(s) that may have inappropriately influenced them in writing this article.

\section{Author's contributions}

J.M.H was the principal investigator of the study and M.N.S was the supervisor, who finalised the manuscript for submission to the journal.

\section{References}

1. Udow SJ, Ann Marrie R, Jackson AC. Clinical features of $\operatorname{dog}$ and bat-acquired rabies in humans. Clinical Infectious Disease 2013; 57(5):689-695.

2. World Health Organisation (WHO). Rabies vaccines: The WHO position paper. World Health Organisation Weekly Epidemiological Record 2018; 16(93):201-220. http://www.who.int/wer (accessed August, 2018).

3. Kalita J, Bhoi SK, Bastia, JK, Lashkar S, Mahadevan A, Misra UK. Paralytic rabies: MRI findings and review of literature. Neurology India 2014; 62(6):662-664.

4. Hampson K, Coudeville L, Lembo T, Sambo M, Kieffer A, et al. Estimating the global burden of endemic canine rabies. PLOS Neglected Tropical Diseases 2015; 9(5): e0003786.

5. Tarantola A. Four thousand years of concepts relating to rabies in animals and humans, its prevention and its cure. Tropical Medical Infectious Diseases 2017; 2:5.

6. Devleesschauwer B, Aryal A, Sharma BK, Ale A, Declercq A, Depraz S, et al. Epidemiology, impact and control of rabies in Nepal: a systematic review. PLOS Neglected Tropical Diseases, 2016; 10(2):1-18.

7. Bishop GC, Durrheim DN, Kloeck PE, Godlonton JD, Bingham J, Speare R et al. Rabies: Guide for the Medical, Veterinary and allied Professions, $2^{\text {nd }}$ edition. Pretoria: Government Printer; 2010.

8. Jibat T, Hogeveen H, Mourits MC. Review on dog rabies vaccination coverage in Africa: a question of $\mathrm{dog}$ accessibility or cost recovery? PLOS Neglected Tropical Diseases 2015; 9(2):1-13.

9. Pye J. Rabies: Prevention strategies for overseas travellers. Nursing Standard 2014; 28:54-58.

10. Polit DF, Beck CT. Nursing research: generating and assessing evidence for nursing practice, 9th edition. New York: Wolters Kluwer Health; 2012.

11. EThekwini Municipality. Integrated Development Plan (IDP) Annual Review 2016/2017; Durban:EThekweni Municipality; 2017. http://www.durban.gov.za/ City_Government/City_Vision/IDP/Documents/ Final\%202016_17\%20IDP\%2029052016.pdf (accessed May, 2017).

12. Silva S, Fraga S. Qualitative research in epidemiology; 2012. http://www.intechopen.com/books/epidemiology-current-perspectives-on-research-andpractice/qualitative-research-in-epidemiology (accessed April, 2018).

13. Creswell JW. Research design: qualitative, quantitative, and mixed methods approaches. $3^{\text {rd }}$ edition. Thousand Oaks, CA: Sage; 2014.

14. Jolley, J. Introducing research and evidence-based practice, $2^{\text {nd }}$ Edition. London: Routledge; 2013.

15. Flick U. An introduction to qualitative research. $4^{\text {th }}$ edition. London: Sage; 2009.

16. Durrheim DN, Ogunbanj GA, Blumberg L, Speare R, Bishop GC. Human rabies: a tragedy that must be prevented. South African Academy of Family Practice/ Primary Care. 2001; 23 (6): 12-19.

17. Lembo T, Hampson K, Kare MT, Eblate E, Knobel, $\mathrm{D}$, Rudovick $\mathrm{R}$, et al. The feasibility of canine rabies elimination in Africa: dispelling doubts with data. PLOS Neglected Tropical Diseases 2010; 4 (2): 3-9.

18. Adedeji AO, Eyarefe O, Babalola ET, Amusan TA, Amande JT, Okonko IO. Why is there still rabies in Nigeria? A review of the current and future trends in the epidemiology, prevention, treatment, control and elim- 
ination. Electronic Journal of Environmental, Agricultural \& Food Chemistry 2010; 9 (8):1283-1307.

19. Weyer J, Msimang-Dermaux V, Janusz TP, le Roux K, Govender P, Coertse J, et al. A case of human survival of rabies, South Africa. Southern African Journal of Infectious Diseases. 2016; 31 (2): 66-68.

20. South Africa. Department of Health. National Core Standards for Health Establishments in South Africa. Pretoria: Government Printer; 2011.
21. Pye J. Rabies: prevention strategies for overseas travellers. Nursing Standard 2014; 28(40): 54-58.

22. Nel L., Le Roux K. and Atlas R. Meeting the rabies control challenge in South Africa. Microbe 2009; 4(2): 6165.

23. EThekwini Municipality. Rabies Action Group. Minutes of the Rabies Action Group 24 November 2011. Durban. Sed quisi offici conse voluptio eaquam reptam in eos endelit expe lique sitiure recest hit versper ectaspe rnamusam erferum expliam rem evelesequae volor mos debis eium 